\title{
Electromagnetic Field of Super High Frequency as a Method for Controling Microbial Exchange of Poultry Feed
}

\author{
Olga M. SOBOLEVA ${ }^{1 * 2}$, Marina M. KOLOSOVA $^{1}$, and Larisa A. FILIPOVICH ${ }^{1}$ \\ ${ }^{1}$ Kuzbass State Agricultural Academy, Kemerovo, Russian Federation \\ ${ }^{2}$ Kemerovo State Medical University, Kemerovo, Russian Federation \\ *Correspondence: meer@yandex.ru
}

\begin{abstract}
Microbial contamination of feed reduces the efficiency of livestock and poultry production, negatively affects the quality of this product. The purpose of the work is to determine the degree of microbial contamination of feed and assess the effectiveness of using the electro-physical method of reducing it. A study of the quality of poultry feed was carried out at the Kemerovo State Agricultural Institute in 2018. The level of general microbial contamination of the studied feed lots was quite high. For feed grain, the total microbial number exceeded the standard indicator by 54 times. The total number of mushrooms for feed was $1.2 \cdot 102 \mathrm{CFU} / \mathrm{g}$, for feed mixtures $-1.9 \cdot 102 \mathrm{CFU} / \mathrm{g}$, for grain of wheat - $1.5 \cdot 103 \mathrm{CFU} / \mathrm{g}$. The total microbial number, respectively: $3.0 \cdot 105 \mathrm{CFU} / \mathrm{g} ; 6.3$. $105 \mathrm{CFU} / \mathrm{g} ; 2.7 \cdot 106 \mathrm{CFU} / \mathrm{g}$. Processing of feed in the electromagnetic field of a traveling microwave wave using the technology of EcoMashService LLC (Russia) allows simultaneously drying and disinfecting the material. The microwave processing regime used in the study (60 kW power, magnetron frequency $915 \mathrm{MHz}$, exposure time 90 seconds) reduced microbial contamination: for compound feed, the decrease in the total microbial number relative to control was 142.9 times, feed mixtures - 7.9 times, wheat grains - 16, 9 times; a decrease in the total number of mushrooms in $4.0 ; 17.3$ and 4.8 times, respectively. The results of the study let us to conclude that the electrophysical method used in the processing of feed for productive poultry effectively reduces their contamination.
\end{abstract}

Keywords: poultry feed, microbiological safety, microwave electromagnetic field, selected mode, effective disinfection.

\section{Introduction}

The feed sanitary quality is determined by the degree of its contamination by representatives of saprotrophic, opportunistic and pathogenic microflora, as well as toxic substances of anthropogenic and biological origin. Feed may be contaminated with pesticide residues that are used in a forage crop cultivation [1, 2], toxic elements released into the environment by industrial enterprises and motor vehicles [3], mycotoxins [4, 5], phytotoxins, nitrates and nitrites [6].

Low productivity, morbidity and death of farm animals are often associated with the contamination of raw materials and feed with pathogenic microorganisms: salmonella, enteropathogenic types of Escherichia coli, toxic strains of clostridia and others $[7,8]$. 
Despite the undoubted successes of recent years in optimizing the feeding of farm animals and poultry, the role of microbial contamination of feed in reducing production efficiency requires additional attention and study [9].

The quantitative and qualitative composition of the microflora of poultry feed is very diverse and is formed under the influence of many factors. First of all, if the feed is a product of processing plant materials, then the epiphytic microflora of these raw materials and located on processing equipment, in workshops, warehouses, and so on, go to a large extent.

Phytopathogenic microorganisms, including mold fungi, constitute a special group of microflora of plant materials [10]. They infect plants even when developing in the field and can produce toxic substances that are diverse in chemical nature - mycotoxins.

Unfortunately, a significant part of the feed produced in Russia contains traces of unwanted microflora, including live saprotrophic, pathogenic and conditionally pathogenic microorganisms, as well as metabolites of toxigenic species. For example, in a long (six-year) experiment, it was shown that a significant part of compound feed for poultry does not meet the requirements of regulatory documentation on the degree of contamination with pathogenic microflora, microscopic fungi, and mycotoxins [11].

One of the methods to reduce the level of microbial contamination of feed and its individual ingredients is the influence of an electromagnetic field of ultrahigh frequency (EMF microwave). Such processing ensures effective neutralization of toxicogenic microorganisms and helps to preserve the necessary technological properties [12-14] improves the physicochemical parameters of products and ensures microbiological safety at the stages of processing and storage of grain and products from it $[15,16]$. The feed is disinfected due to both the direct action of the microwave on microorganisms, leading to their death, and indirectly due to an increase in the temperature of the medium in combination with the action of the generated water vapor [14].

The purpose of the work is to determine the degree of microbial contamination of feed for poultry and evaluate the effectiveness of the electro-physical method of its reducing.

\section{Materials and Methods}

A study of the quality of feed for poultry treated with microwave radiation using the technology of EcoMashService LLC (Russia) was carried out at the Kemerovo State Agricultural Institute in 2018.

Technological line "Wave 100", developed by EcoMashService LLC, is a high-tech, environmentally friendly, energy-efficient complex that allows for 90 seconds carrying out efficient processing of various, including forage feed, materials. Productivity of the installation can reach up to $100 \mathrm{t} /$ day at the consumed power of electricity of the order $50 \mathrm{~kW} / \mathrm{t}$ of material. Simultaneous drying and disinfection occurs at a universally selected regime of dielectric heating in electromagnetic fields of a traveling microwave wave and at a continuous movement of material in a rotating dielectric retort tube installed in the waveguides of the drying chamber of the microwave path. The following microwave processing mode was used in the work: power - $60 \mathrm{~kW}$, magnetron frequency $-915 \mathrm{MHz}$, exposure - $90 \mathrm{sec}$. 
Objects of the study were the following samples of poultry feed:

- compound feed for laying hens KK-1 (GOST R 51581-2001). According to the manufacturer's information, it includes wheat bran, fodder grain product of category II, wheat, chalk, sunflower cake, salt, premix P1-2;

- granular feed mixture of plant origin (TU 9295-001-21432851-01), including wheat bran and crushed grain mix;

- $\quad$ spring wheat of the grade 5 (GOST 9353-2016 "Wheat. Technical conditions").

Sampling was carried out according to GOST 13496.0-2016 "Compound feed, compound feed raw materials. Sampling methods. "The prepared samples were divided into two equal parts - the control (without processing) and experimental (processed in the microwave field at a given mode). The mass of the combined sample was $4 \mathrm{~kg}$ for each type of feed (feed, feed mixture, feed grain), the weight of the control and experimental samples was $2 \mathrm{~kg}$.

Determination of the total microbial number $(\mathrm{TBC})$, Escherichia coli bacteria $(\mathrm{ECB})$ and salmonella was carried out in accordance with the Rules for bacteriological research of feed (1975) and GOST ISO 7218-2015 "Microbiology of food and animal feed. General requirements and recommendations for microbiological research." The total number of fungi (TNF) was determined according to GOST 10444.12-2013 "Microbiology of food and animal feed. Methods for detecting and counting the number of yeast and molds." In this case, preliminary dilutions were prepared in accordance with GOST R 51426-2016 "Microbiology. Feed, compound feed, compound feed raw materials. General guidelines for the preparation of dilutions for microbiological research." The following nutrient media were used to determine these indicators by cup methods: Saburo, Endo ("Nutrient media", RF), Kessler, KMAFanM ("Biocompas-S", RF), bismuth-sulfite agar ("Microgen", RF). The repetition of the experiment is threefold analytical. The results are presented as arithmetic means; the significance of differences compared with the control was found by the F-criterion at a significance level of 0.05 .

\section{Results and Discussion}

Among the various indicators of microbiological contamination of feed products, the following should be considered the main ones: total microbial number (TMN), total number of fungi (TNF) and salmonella, E. coli (Escherichia coli). These indicators are indicated in the regulatory documentation (Table 1).

The level of microbial contamination of the presented food samples was different (Table 2). The highest concentration of bacteria was observed for feed grain of wheat $2.7 \cdot 10^{6} \mathrm{CFU} / \mathrm{g}$, slightly lower for feed mixtures $-6.3 \cdot 10^{5} \mathrm{CFU} / \mathrm{g}$, which is higher than the permissible level. The total contamination of feed for laying hens was $3.0 \cdot 10^{5} \mathrm{CFU} / \mathrm{g}$ and corresponded to the requirements of CR EEU.

In relation to sanitary-indicative ECB and salmonella, all three presented samples of food are safe - indicator microorganisms in the required volumes of food were not found. 
Table 1. Requirements for compound feeds for productive poultry according to the draft of the Customs Regulation of the Eurasian Economic Union (CR EEU) "On the safety of feed and feed additives"

\begin{tabular}{|c|c|}
\hline Indicator & Allowable Level \\
\hline \multicolumn{2}{|l|}{ Microbiological indicators: } \\
\hline TNF, CFU/g, not more than: & $5 \cdot 10^{4}$ \\
\hline TMN, CFU/g, not more than: & $5 \cdot 10^{5}$ \\
\hline \multicolumn{2}{|c|}{ Presence of pathogenic microorganisms: } \\
\hline Salmonella in 50,0 g & not allowed \\
\hline E. coli в 1,0 г & not allowed \\
\hline pathogenic Escherichia in 50,0 g & not allowed \\
\hline
\end{tabular}

Table 2. Bacteriological characteristics of the studied feed after microwave processing

\begin{tabular}{l|l|c|c|c}
\hline \multirow{2}{*}{ Type of feed } & \multirow{2}{*}{ Indicator } & Unit & \multicolumn{2}{c}{ Feed Test Results } \\
\cline { 3 - 5 } & & & Control & After \\
microwave
\end{tabular}

Microwave treatment has led to a decrease in microbial contamination of all the studied feeds: 142.9 times for compound feed, 7.9 times for feed mixtures, and 16.9 times for wheat grains (Table 3). The complete destruction of the bacterial component of the microflora of feeds under the used microwave treatment regime was not achieved - the remaining viable bacteria are represented, for the most part, by representatives of the genus Bacillus. They are capable of spore formation and, apparently, are resistant to the mode of electrophysical influence used in the work. 
A stronger decrease in the number of bacteria for feed compared with other samples is apparently due to its composition. Molecules of water and lipids differ in the maximum absorption of electromagnetic waves relative to other organic and inorganic compounds [17]. The composition of the feed, in contrast to the feed mixture, includes sunflower cake. This ingredient leads to an increase in the total amount of fats in the feed and accordingly increases their absorption capacity with respect to electromagnetic radiation.

Mycological analysis of the studied feed samples showed that the total number of fungi in them is small and below the upper limit of the permissible range (Table 2). However, even for feeds of this quality, microwave processing can be useful, since each achieved level of microbial load reduction provides an additional advantage when storing feeds, especially in the case of uncontrolled deterioration of storage conditions. While the contamination of feed with mycotoxins is significant, the content of them can grow along with an increase in the number of their producers.

The maximum in the experiment the number of spores of micromycetes was noted for untreated wheat grain - $1.5 \cdot 10^{3} \mathrm{CFU} / \mathrm{g}$, the minimum - for compound feed $-1.2 \cdot 10^{2}$ $\mathrm{CFU} / g$. Electro-physical effects have led to a decrease in the number of viable microscopic fungi. The difference with control was 4.0 times for compound feed, 4.8 times for wheat grain, and 17.3 times for feed mixtures.

Among the identified micromycetes, the genera Penicillium and Aspergillus (warehouse molds, some of which produce ochratoxin A), Fusarium (belongs to the category of field molds, some species produce T-2 toxin) were identified.

\section{Conclusions}

The microflora of the studied feed samples is represented by both a phyto-pathogenic and a saprotrophic component, however, no pathogenic microorganisms were found for humans and animals. By the value of the TMN, feed grain of wheat and feed mixture did not meet the permissible level. Microwave treatment reduced the microbial contamination of all the studied feeds: for compound feed, the decrease in TMN with respect to control was 142.9 times, feed mixtures - 7.9 times, wheat grains - 16.9 times; reduction in TNF - 4.0; 17.3 and 4.8 times, respectively. Thus, the electrophysical method of microwave processing of feed on the equipment of EcoMashService LLC in the used mode (power - $60 \mathrm{~kW}$, magnetron frequency - $915 \mathrm{MHz}$, exposure - $90 \mathrm{sec}$.) has shown its effectiveness in reducing microbial contamination of feed for poultry.

\section{References}

(1) Kumar, M.; Chand, R.; Shah, K. Mycotoxins and Pesticides: Toxicity and Applications in Food and Feed. In Microbial Biotechnology; Patra, J. K., Das, G., Shin, H.-S., Eds.; Springer Singapore: Singapore, 2018; pp 207-252. https://doi.org/10.1007/978981-10-7140-9_11.

(2) Pavlova, N. S.; Galimova, V. P.; Blinov, N. V.; Brichko, N. A.; Dorozhkin, V. I. The Study of Accumulation of Pesticides in the System "Soil-Plant" and the Possibility of Obtaining Safe Feed (in Russian). Russian Journal of the Problem of Veterinary Sanitation, Hygiene and Ecology 2017, 3, 68-73. 
(3) Zehra, A.; Sahito, Z. A.; Tong, W.; Tang, L.; Hamid, Y.; Khan, M. B.; Ali, Z.; Naqvi, B.; Yang, X. Assessment of Sunflower Germplasm for Phytoremediation of LeadPolluted Soil and Production of Seed Oil and Seed Meal for Human and Animal Consumption. Journal of Environmental Sciences 2020, 87, 24-38. https://doi.org/10.1016/j.jes.2019.05.031.

(4) Trufanov, O.; Kotik, A.; Trufanova, V. Mycotoxins in Feed for Poultry (in Russian). Animal Husbandry of Russia 2017, 7, 5-8.

(5) Hassan, Z. U.; Al-Thani, R. F.; Migheli, Q.; Jaoua, S. Detection of Toxigenic Mycobiota and Mycotoxins in Cereal Feed Market. Food Control 2018, 84, 389-394. https://doi.org/10.1016/j.foodcont.2017.08.032.

(6) Gupta, P. Feed Contaminant Toxicity. In Concepts and Applications in Veterinary Toxicology; Springer International Publishing: Cham, 2019; pp 279-287. https://doi.org/10.1007/978-3-030-22250-5_12.

(7) Rönnqvist, M.; Välttilä, V.; Ranta, J.; Tuominen, P. Salmonella Risk to Consumers via Pork Is Related to the Salmonella Prevalence in Pig Feed. Food Microbiology 2018, 71, 93-97. https://doi.org/10.1016/j.fm.2017.03.017.

(8) Abudabos, A. M.; Alyemni, A. H.; Dafalla, Y. M.; Khan, R. U. The Effect of Phytogenics on Growth Traits, Blood Biochemical and Intestinal Histology in Broiler Chickens Exposed to Clostridium Perfringens Challenge. Journal of Applied Animal Research 2018, 46 (1), 691-695. https://doi.org/10.1080/09712119.2017.1383258.

(9) Woutersen, R. A.; Waalkens-Berendsen, I.; Wester, P.; Rietjens, I. M. C. M. The Assessment of the Safety for the Consumer of Feed Additives and Additives Added to Foods of Animal Origin. In ECVPH Food safety assurance; Smulders, F. J. M., Rietjens, I. M. C. M., Rose, M., Eds.; Wageningen Academic Publishers: The Netherlands, 2019; Vol. 7, pp 99-117. https://doi.org/10.3920/978-90-8686-8773_04.

(10) Müller, T.; Ruppel, S.; Behrendt, U.; Lentzsch, P.; Müller, M. E. H. Antagonistic Potential of Fluorescent Pseudomonads Colonizing Wheat Heads Against Mycotoxin Producing Alternaria and Fusaria. Frontiers in Microbiology 2018, 9, 2124. https://doi.org/10.3389/fmicb.2018.02124.

(11) Shabunin, S. V.; Belyaev, V. I.; Efanova, L. I.; Alyokhin, Yu. N. Biological Toxicants of Alimentary Origin (in Russian). Veterinary Medicine 2016, 1, 47-50.

(12) Vasilyev, A. A.; Samarin, G. N.; Vasilyev, A. N. Processing Plants for Post-Harvest Disinfection of Grain. In Intelligent Computing and Optimization; Vasant, P., Zelinka, I., Weber, G.-W., Eds.; Springer International Publishing: Cham, 2020; Vol. 1072, pp 501-505. https://doi.org/10.1007/978-3-030-33585-4_49.

(13) Dolgov, G. L.; Belov, A. A.; Sharonova, T. V. Installation for the disinfection of animal feed (in Russian). Bulletin of ChSPU im. And. I. Yakovleva 2013, 4 (80), 66-69.

(14) Ikhlov, B. L.; Melnichenko, A. V.; Oshchepkov, Ay. The action of a microwave electromagnetic field on microorganisms (in Russian). Bulletin of New Medical Technologies 2017, 2, 141-146. 
(15) Kondratenko, E. P.; Soboleva, O. M.; Sukhikh, A. S. Influence of Microwave Electromagnetic Field on the Fatty Acid Composition of Seedlings Hordeum Sativum (in Russian). Khimiya Rastitel'nogo Syr'ya (Chemistry of Plant Raw Materials) 2017, 3, 93-99.

(16) Syrovatka, V. I. Promising Technologies for the Production of Animal Feed (in Russian). Zootechny 2016, 10, 7-12.

(17) Myshkin, V. F.; Myshkin, V. F.; Vlasov, V. A.; Khan, V. A.; Shiyan, L. N.; Polchenko, V. S. Structure and Properties of Water Irradiated with Microwave Radiation (in Russian). Political Mathematical Electronic Scientific Journal of the Kuban State Agrarian University 2012, 81, 64-75.

\section{Information about Authors}

Olga Mikhailovna SOBOLEVA: Ph.D. in Biology, (1) Associate Professor, Department of Agrobiotechnology, Faculty of Agrobiotechnology, Kuzbass State Agricultural Academy; 5 Markovtsev Str., Kemerovo, 650056, Russia; (2) Associate Professor, Department of Microbiology, Immunology and Virology, Faculty of Medicine and Prevention; 22a Voroshilov Str., Kemerovo, 650056, Russia, e-mail: meer@yandex.ru.

Marina Mikhailovna KOLOSOVA: Ph.D. in Chemistry, Associate Professor, Department of Landscape Architecture, Faculty of Engineering, Kuzbass State Agricultural Academy; 5 Markovtsev Str., Kemerovo, 650056, Russia; e-mail: komar.54@yandex.ru.

Larisa Anatolyevna FiliPOVicH: Ph.D. in Education, Associate Professor, Department of Mathematics, Physics and Information Technology, Faculty of Engineering, Kuzbass State Agricultural Academy; 5 Markovtsev Str., Kemerovo, 650056, Russia; e-mail: laf.47@yandex.ru. 